\title{
The Evolution of Ethical Care: From Therapy to Research
}

\author{
Joseph Carnevale ${ }^{1}$
}

\begin{abstract}
For the majority of human history, practicing medicine has been guided by ethical codes shaped according to social customs. Research, on the other hand, has been left unaddressed for centuries without rules or regulations resulting in the abuse of countless vulnerable individuals. However, the horrors displayed in the past century, especially in Nuremberg and Tuskegee, could be ignored no longer, as the world public and not just physicians addressed the ethics of care. Present in countless codes and guidelines regulating therapeutic care, the fundamental thread of beneficence was reemphasized and resulted in the transition from paternalism to a new found respect for autonomy. With this paradigm shift came a boom in ethical concern around the world, providing protection for the vulnerable members of our globalized society.
\end{abstract}

\section{INTRODUCTION: THERAPY VS. RESEARCH}

Riding through the western Kenyan countryside, physicians, nurses, and I headed to a remote village on the Ugandan border. Unfortunately, western Kenya and eastern Uganda are one of the many rural areas lacking in largescale interventions of humanitarian aid. Nevertheless, Intercommunity Development and Involvement (ICODEI) provides for this underserved region by mobilizing international volunteers to empower the local Kenyan economy, education, and healthcare. ${ }^{2}$ The mobile health clinic provided essential medical therapy for hundreds of people who would otherwise have little or no chance of survival. Although I am not a physician or licensed health care provider of any kind, local Kenyans looked to me with trusting eyes for help. I was there to learn and do what I could to help.

One man begged me to come to his village and cure his daughter of polio. Pointing off into the distance, the man urged me to follow him. Whether it was the color of my skin or my association with ICODEI, this man trusted me unconditionally to do what was best for him and his family. As it pained me to admit I could not help, his helplessness consumed me. While in Africa, I realized the degree of desperation of those consumed with poverty. Although we were providing medical services, the vulnerability of this population became clear. Sadly, with vulnerability comes unethical manipulation. Under the guise of therapeutic treatment, physicians acting as researchers have continued to use others as means to their own end. My experiences volunteering around the world have clarified the important distinction between therapy and research. Therapy as it has existed for millennia, is treatment aimed toward enhancing an individual's well being and associated with the Hippocratic ethic. On the other hand, research uses individuals to enhance the present or future society's wellbeing, and contradicts the Hippocratic ethic. Unfortunately, this distinction was not emphasized by the international medical or research community until 1946, and not universally accepted or enforced until years later.

The advancement of medicine toward enhancing human health requires the participation of individuals in research. Despite the opposition to such research, two arguments have flourished in justifying the use of humans in clinical research. First, "human research appeals to the principle of beneficence" because the individual harms of participating in a study are outweighed by the potential societal benefits. However, as we shall, the nature and magnitude of individual harms varies significantly depending on the researcher's ethic. Second, continued human involvement in research appeals to the principle of justice. "Every person currently alive is the beneficiary of earlier human subjects' involvement in research." For example, those who participated in experimental trails in the development of antibiotics, the Polio vaccine, etc., have directly benefited the human condition. Therefore, a concern for justice requires continued individual involvement in research for the betterment of society. ${ }^{3}$ Appealing to arguments of beneficence and justice, human involvement in clinical research is vindicated; however, as the historical accounts will show, the nature of the study cannot sacrifice an individual's autonomy.

Research as it pertains to humans has complemented and enhanced scientific exploration for centuries. However, a general disregard for those being experimented on went unnoticed and consumed the researchers for the majority of that time. Throughout the past century various publicized injustices have resulted in today's growing concern for autonomy and ethical medical treatment, giving rise to various international bioethical boards and setting the standard of care for all humans.

${ }^{1}$ Corresponding Author: joseph_carnevale@brown.edu

${ }^{2}$ Intercommunity Development and Involvement (ICODEI). <www.volunteerkenya.org>

${ }^{3}$ Beauchamp, et al. 


\section{Historical Perspective}

Although some areas of patient care are relatively uncontroversial, others make a judgment in areas of ongoing controversy amongst competing ethical obligations. For thousands of years, the obligations of the clinician have been guided by various codes of conduct. Beginning in $1750 \mathrm{BCE}$, the king of Babylon, Hammurabi, put forth the first written compilation of regulations aimed to guide medical ethics, named the Code of Hammurabi. According to this code, a doctor's "hands shall be cut off" if he causes the death of a patient while performing a new operation. ${ }^{4}$ Needless to say, such a punishment for medical error, under ethical pretenses or not, could not be justified in society today. Namely, the punishment does not fit the crime; however, nearly four thousand years ago, Babylonian society needed to control and regulate medical procedures so to protect the patient from an otherwise unqualified physician.

The next recorded and possibly most respected ancient ethical guidance is the Hippocratic Oath. Established in the fourth century BCE by Hippocrates, the Oath of Hippocrates continues to be upheld and respected by physicians around the world. Although it has become highly symbolic, the Hippocratic ethic maintains two fundamental principles of medical ethics: beneficence and non-maleficence. "I will ... benefit my patients according to my greatest ability and judgment, and I will do no harm or injustice to them." ${ }^{5}$ These complementary principles emphasize the primary responsibilities of a physician to his or her patients.

Due to its religious connotations, many medical schools do not employ the oath but promote the Hippocratic ethic. In other words, between the physician and the patient there is, or at least should be, a relationship based on trust, also known as a fiduciary relationship. Overall, the physician should use his/her clinical knowledge and abilities in the best interest of the patient. Under the old paternalistic system, the physician would do what he/she thought was best, without patient approval. Nowadays, with the emphasis on patient autonomy, physicians recommend, and patients either accept or decline the advice. Treatment could not be forced upon a patient. However, when treatment options are not clear, a physician may suggest an experimental medication. Is there a distinction between experimentation and research? Yes, experimenting with a potentially helpful drug is still being done with an eye for the patient, maintaining the Hippocratic ethic. Essentially, the difference between the Hippocratic ethic and the research ethic is that research looks to the future and to the welfare of others, not the specific patient. Therefore, ethical research requires oversight and contemporary history has shown the necessity for rules and regulations.

With the Code of Hammurabi and the Hippocratic Oath as a foundation, the general concern for clinical ethics erupted around the world with the creation of numerous oaths and codes aimed toward normalizing the common moral into comprehensive ethical guidelines, and even in some cases into written law. From the third century Oath of Aspah in Israel to the Japanese 17 Rules of Enjuin in 1500 AD, dozens of ethical codes concerning ethical clinical care were created. However, these so-called 'ethical' codes subscribed to paternalism and generally disregarded a patient's autonomy. This left little protection for individuals involved in the monumental amount of unethical research being conducted.

According to the Encyclopedia of Bioethics, Dr. Zabdiel Boylston, in the early eighteenth century, was one of the first to conduct documented systematic research. In his effort to alleviate smallpox, Dr. Boylston injected children, including his own son, with the weakened infectious agent. ${ }^{6}$ Even though research studies such as this have led to countless beneficial medications and vaccines, one cannot disregard the blatant unethical action of infecting children with a deadly virus. As the involvement of human subjects in research increased for decades so did the atrocious treatment of research participants. Eventually the fuse of unethical research reached a critical point in the 1940s, causing a global explosion of standardized ethical guidelines.

\section{CONTEMPORARY PERSPECTIVE}

The first time the public really looked at research was after Nuremberg because of the enormity that went on in German concentration camps and Japanese prisoner of war camps throughout the Second World War. Although ethical research was uncommon for centuries, the Third Reich and their SS physicians preformed acts of cruelty that shook humanity's moral fiber and set in motion the universal concern for bioethics.

\footnotetext{
4 "The Avalon Project : Code of Hammurabi." Avalon Project - Documents in Law, History and Diplomacy. Trans. L. W. King. 2008. Web. 15 Nov. 2010.

5 "Greek Medicine: The Hippocratic Oath." National Library of Medicine - National Institutes of Health. Trans. Michael North. 2002. Web. 15 Nov. 2010.

${ }^{6}$ Brieger, Gert H. "Human Experimentation: History." In Warren T. Reich, ed. Encyclopedia of Bioethics. New York: Free Press, 1978.
} 
From 1939 to 1945, Nazi physicians preformed numerous experiments, ranging from high altitude to freezing to poisoning, that were highly publicized bringing the ethics of research to center stage. Even Adolf Hitler, in 1941, prohibited gassing of disabled patients because the procedure had become too public; nevertheless, these experiments were decentralized and continued. ${ }^{7}$ It is difficult to imagine such disregard for autonomy and disrespect for others. The first victims were termed "useless eaters" and a "burden to the German war machine." disabled children and institutionalized adults, particularly those individuals who were the easiest to take advantage of. Of the numerous physicians brought to justice at the Nuremberg Trials, Hermann Pfannmüller was a key player in the phase of "wild euthanasia" and childhood experimentation in Eglfing-Haar, outside Munich. In a Bavarians schoolteacher's testimony, Pfannmüller and his children's ward were described:

I remember ...the sense of his speech because it was, either due to cynicism or clumsiness, surprisingly frank: 'For me as a national socialist, these creatures obviously represent only a burden for our health national body. We do not kill with poison, injections, etc., because that would only provide new slanderous campaign material for the foreign press and certain gentlemen in Switzerland. No, our method is, as you can see, much simpler and far more natural.' As he spoke these words, Pfannmüller... pulled a child from its crib. Displaying the child like a dead rabbit, he pontificated with the air of a connoisseur and a cynical smirk something like this: 'With this one, for example, it will still take two or three more days.' I can still clearly visualize the spectacle of this fat and smirking man with the whimpering skeleton in his fleshy hand, surrounded by other starving children. ${ }^{9}$

Although he was considered a medical expert for selecting victims, Pfannmüller and others were charged with involvement in Nazi human experimentation and crimes against humanity. In 1947, the "Trials of War Criminals before the Nuremberg Military Tribunals" (NMT) concluded with the preservation of justice, sentencing seven doctors to death and many others to prison. Nuremberg was the first time that the world pubic forum came forward and formalized guidelines in an effort to return to the Hippocratic tradition.

Out of Nuremberg and other horrors around the world came an attempt to establish guidelines of how research could be carried out in an ethical way. In 1947, Dr. Leo Alexander submitted six principles of legitimate medical research to which the Council for War Crimes added four more, resulting in the complete ten points of the Nuremberg Code. First of all, scientific questions had to be of scientific value to qualify for human experimentation. Testing how long someone can withstand freezing temperatures is not of any scientific merit. Second, the research had to be of some benefit to humanity, rather than just satisfying ones curiosity. Lastly and most importantly, Nuremberg established the need for consent. Research participants must be fully informed, agree to participate, and continue to be informed throughout any and all research. Nuremberg also emphasized the importance of protecting patient confidentiality. Although these guidelines were drafted and presented to the international community so to protect patient autonomy, the Nuremberg Code was not incorporated into any body of laws, neither German nor American. Therefore, despite these steps in the right direction, Nuremberg was not enough protection and other codes would come along to fill in the holes.

Throughout the late 1940s, 50s, and 60s, the regulations sparked by the Nuremberg Trials proved not enough to adequately protect neither patients nor participants. As a result, the World Medical Association (WMA) established the Declaration of Helsinki in 1964. Firmly addressing international bioethics, the Declaration of Helsinki started out looking at the consent portion of Nuremberg and focused on populations of people who could not give consent, such as children, mentally challenged and institutionalized adults. In an attempt to protect this vulnerable population, the declaration introduced the notion of surrogate, or proxy, consent. For example, cancer treatment, especially in the mid $20^{\text {th }}$ century, relied on research and human participation. Childhood cancers were of particular interest; however, obtaining informed consent from these young individuals became a challenge. Surrogate consent properly allowed guardians to submit their children into clinical trials. Nowadays, nearly $90 \%$ of all American children with cancer are immediately introduced into research studies. As a result, the "5-year survival rates for all childhood cancers combined increased from 58.1 percent in 1975-77 to 79.6 percent in 1996-2003." ${ }^{\text {"10 }}$ Clearly,

\footnotetext{
${ }^{7}$ Nicosia, Francis R., and Jonathan Huener, eds. Medicine and Medical Ethics in Nazi Germany. New York: Berghahn, 2002. Print.

${ }^{8}$ Beauchamp, Tom L., LeRoy Walters, Jeffrey P. Kahn, and Anna C. Mastroianni, eds. Contemporary Issues in Bioethics. Belmont, CA: Thomson/Wadsworth, 2008. Print.

${ }^{9}$ Nicosia, Francis R., and Jonathan Huener, eds. Medicine and Medical Ethics in Nazi Germany. New York: Berghahn, 2002. Print.

${ }^{10}$ National Cancer Institute. U.S. National Institutes of Health. <www.cancer.gov>
} 
research has extraordinary potential; however, it would take another vile injustice to raise the national and international standards of care.

Throughout the majority of the $20^{\text {th }}$ century, countless scientists, even medical doctors, have performed acts of horrifying belligerence. Although we are quick to point the finger at the Germans and the Japanese, American scientists, physicians, and the United States Government, according to President William J. Clinton, "did something that was wrong - deeply, profoundly, morally wrong." ${ }^{11}$ Between 1932 and 1972, the U.S. Public Health Service manipulated and coerced nearly 400 African Americans to participate in a research study, testing the untreated effects of syphilis. Although antibiotics became the standard treatment for syphilis by 1947, the researchers withheld this known treatment. As a result, participants lived with the disease for decades and it is "estimated that 28 of the original syphilitic group had died of syphilis during the study." 12 Even though penicillin was given, apologies were made, and compensation was dealt, was justice served? Something needed to be learned from the events in Tuskegee, Mississippi and more importantly implemented for the future.

Unsatisfied with its level of bioethical concern, the United States took individual measures to maintain and regulate medical practices, clinical or research. In 1966, the American medical Association (AMA) adopted guidelines for clinical research. Then, the National Research Act was passed in 1974, creating the National Commission for the Protection of Human Subjects of Biomedical and Behavioral Research. Driven by social and political concern, this commission was charged along with the U.S. Department of Health, Education, and Welfare, known today as the U.S. Department of Health and Human Services (HHS), to tighten regulations on human testing. Finally, in 1979, Dan Harms and HHS released the Belmont Report and established the "Common Rule." The Belmont Report outlined the three fundamental principles of bioethics: respect for autonomy, beneficence, and justice. More important than reiterating past principles, the Belmont Report implemented Institutional Review Boards (IRB). IRBs are diverse committees of professionals aimed at determining the nature of the research project. Specifically, the IRB should fairly examine the social, economic, moral, and ethical implications of performing the research on humans. ${ }^{13}$ Despite the fact that IRBs are susceptible to manipulation and corruption, the Belmont Report brought with it something incorruptible, the "Common Rule." This past century's increase in concern for bioethics has established a 'common sense' when it comes to research and therapy. That is to say, the ideas of autonomy, beneficence, and justice have been pounded into the public's face over and over again since Nuremberg so that such principles have become 'common sense' to new generations. Hopefully, the current generation will set the example for those to come by upholding this "Common Rule."

Nevertheless, when research regulations became too rigorous in the industrialized, developed world, researchers took their work overseas to the developing world where regulations were scarce and human subjects were eager to participate. In the developing world, there are minimal medical personnel and even less medical resources. Consequently, when a rural farmer sees someone in a white coat, he may assume the researcher is acting in the best interest of his daughter with polio. However, many vulnerable citizens of the developing world do not necessarily understand the distinction between therapeutic care and research.

Since 1964, The Declaration of Helsinki has been revised several times, most recently in 2008. Numerous revisions are a result of the dynamic nature of bioethics as it struggles to keep up with the changing world. According to the New England Journal of Medicine, "residents of impoverished, postcolonial countries, the majority of whom are people of color, must be protected from potential exploitation in research. Otherwise, the abominable state of health care in these countries can be used to justify studies that could never pass ethical muster in the sponsoring country." ${ }^{, 4}$ In 2000, the firth revision was aimed toward protecting the people of the developing world. Specifically, the 200 revision emphasized the importance of implementing the research benefits within the subjects' community. Furthermore, if equipoise could not be reached for a drug trial, placebos were prohibited from being used in studies for which there is a know therapy. This is a direct result of various unethical HIV retroviral clinical trials conducted throughout Sub-Saharan Africa.

${ }^{11}$ Clinton, William J. "In Apology for Study Done in Tuskegee." The White House, Washington DC. 16 May 1997. Speech.

${ }^{12}$ Beauchamp, et al.

${ }^{13}$ Mazur, Dennis John. The New Medical Conversation: Media, Patients, Doctors, and the Ethics of Scientific Communication. Lanham: Rowman \& Littlefield, 2003. Print.

${ }^{14}$ Lurie, Perer, and Sideny M. Wolfe. "Unethical Trials of Interventions to Reduce Perinata Transmission of the Human Immunodeficiency Virus in Developing Countries" The New England Journal of Medicine 337 (1997): 85365. Print. 
By the end of the last century, nearly 35 million men, women and children were infected with HIV/AIDS around the world. ${ }^{15}$ Although numerous retroviral medications have been synthesized to treat this population, treatment is heavily skewed toward the developed world and practically intangible in many parts of the developing world. Unfortunately, nearly $70 \%$ of people with HIV/AIDS live in sub-Saharan Africa with little or no hope for therapy. ${ }^{16}$ According to the United Nations, one of the best ways to combat this epidemic is to intervene during pregnancy. "Each year an estimated two million H.I.V.-infected women worldwide become pregnant" and nearly 680,000 babies were born with AIDS in 1997, "thrusting mother-to-child transmission to the center stage" of this global pandemic. ${ }^{17}$ Although drugs have been created, such as AZT, to avoid natal transmission, researchers have employed placebos to test against new experimental medication. Like in Tuskegee, this withholding of known treatments is purely unethical and has raised bioethical debates around the world.

\section{RESEARCH ETHICS TODAY}

According to the Ethox Centre at the University of Oxford, "ethics involves reflecting on moral values and reasoning about their implications for practice." The proper practice of ethics includes exploring the moral reasons for proceeding in a particular direction, being able to make moral judgments, developing models of good practice informed by reflections, and being sensitive to and aware of the moral dimensions.

Overall, there are three contrasting approaches to the ethics of research: autonomy, duty of care, and consequentialist. An autonomic approach to research ethics stresses the importance of consent, but more importantly that the consent is 'valid'. In this view, the main duty of any researcher and institutional review board is to ensure 'valid' consent, meaning the individual remains fully informed, competent, and voluntarily choosing to participate throughout the study.

Alternatively, the duty of care approach, which usually attracts clinicians, emphasizes the responsibility of researchers to care for the participants. Although the duties will vary depending on point of view, one common duty is to ensure that participants are not exposed to high risk of harm. In contrast with autonomy, duty of care may require researchers to override the participants' autonomy in order to protect them from more than minimal risk of harm.

Finally, a consequentialist approach judges whether a research project is "ethical on the basis of the foreseeable consequences of the research." This standpoint places all moral weight on the benefits and harms to both participants and those patients who would benefit in the future. If the benefits of research outweigh the harms involved, consequentialists believe the research to be ethical. In contrast to autonomy and duty of care, consequentialists view harm to individuals during research may sometimes be justified by the likelihood of benefits to the 'public interest.'

In conclusion, physicians have been serving the public for thousands of years. Although various codes and oaths were established to regulate therapeutic care, little attention was given to the countless number of individuals forcibly or unknowingly involved in research. In the past two centuries, various injustices have transpired that have led to the establishment of national and international research ethics boards, guidelines and committees. Nevertheless, if the progression and manifestations of morality in medical ethics has taught us anything, we should remember that morals change with changing times and the current ethical standards should continue to promote respect for autonomy, beneficence, and justice for all humanity. Hopefully, when I return to the developing world as a licensed physician, I will be guided by these principles to morally serve those in need.

\section{REFERENCES}

[1] Altman, Lawrence K. “U.N. Plans to Treat 30,000 H.I.V.-Infected Pregnant Women.” The New York Times 30 June 1998. Print.

[2] Beauchamp, Tom L., LeRoy Walters, Jeffrey P. Kahn, and Anna C. Mastroianni, eds. Contemporary Issues in Bioethics. Belmont, CA: Thomson/Wadsworth, 2008. Print.

[3] Brieger, Gert H. "Human Experimentation: History.” In Warren T. Reich, ed. Encyclopedia of Bioethics. New York: Free Press, 1978.

[4] Clinton, William J. "In Apology for Study Done in Tuskegee." The White House, Washington DC. 16 May 1997. Speech.

\footnotetext{
${ }^{15}$ World Health Organization.

${ }^{16}$ Ibid.

${ }^{17}$ Altman, Lawrence K. New York Times.
} 
[5] "Greek Medicine: The Hippocratic Oath." National Library of Medicine - National Institutes of Health. Trans. Michael North. 2002. Web. <http://www.nlm.nih.gov/hmd/greek/greek_oath.html>.

[6] Loue, Sana C., and Earl Pike, eds. Case Studies in Ethics and HIV Research. Cleveland: Springer, 2007. Print.

[7] Lubanga, Reuben. Intercommunity Development and Involvement (ICODEI). <www.volunteerkenya.org>

[8] Lurie, Perer, and Sideny M. Wolfe. "Unethical Trials of Interventions to Reduce Perinata Transmission of the Human Immunodeficiency Virus in Developing Countries" The New England Journal of Medicine 337 (1997): 853-65. Print.

[9] Mazur, Dennis John. The New Medical Conversation: Media, Patients, Doctors, and the Ethics of Scientific Communication. Lanham: Rowman \& Littlefield, 2003. Print.

[10] Murphy, Timothy F. Case Studies in Biomedical Research Ethics. Cambridge: MIT, 2004. Print.

[11] National Cancer Institute. U.S. National Institutes of Health. <www.cancer.gov>

[12] Nicosia, Francis R., and Jonathan Huener, eds. Medicine and Medical Ethics in Nazi Germany. New York: Berghahn, 2002. Print.

[13] Parker, Mike, Susan Bull, Jantina De Vries, and Paulina Tindana. "Ethics and Global Health." University of Oxford Global Health Summer School. Jesus College, Oxford, UK. July 2010. Lecture.

[14] "The Avalon Project : Code of Hammurabi." Avalon Project - Documents in Law, History and Diplomacy. Trans. L. W. King. 2008. Web.<http://avalon.law.yale.edu/ancient/hamframe.asp>.

[15] "WHO | Data and Statistics." World Health Organization. Web. <http://www.who.int/hiv/data/en/>. 